\title{
Assessment of Risk Factors on Eye Dryness in Young Adults Using Visual Display Device both in Contact Lens Wearers and Non-wearers
}

Ekin Altinbas ( $\nabla$ altinbasekin@gmail.com )

Acıbadem University https://orcid.org/0000-0003-4954-305X

\section{Alperen Elibol}

Acibadem Mehmet Ali Aydinlar University: Acibadem Universitesi

Göktuğ Fıratlı

Acibadem University Faculty of Medicine: Acibadem Universitesi Tip Fakultesi

Cemre Ayhan

Acibadem Mehmet Ali Aydinlar University: Acibadem Universitesi

\section{Ali Riza Cenk Celebi}

Acibadem University - Kerem Aydınlar Campus: Acibadem Universitesi https://orcid.org/0000-00027952-1241

\section{Research Article}

Keywords: Dry eye disease, Contact lens use, Computer vision syndrome, Visual display device

Posted Date: January 28th, 2022

DOI: https://doi.org/10.21203/rs.3.rs-1205548/v1

License: (c) (1) This work is licensed under a Creative Commons Attribution 4.0 International License. Read Full License 


\section{Abstract \\ PURPOSE}

Researchers are interested in examining the impact of visual display devices (VDDs) on the development of dry eye illness because their use is becoming more common among college students. The goal of this study was to see if there was a link between certain risk factors and the development of eye dryness in VDDs using young adults who wore contact lenses and those who didn't.

\section{METHODS}

The self-administrated survey was hosted in Google Forms, sent via e-mail to the participants. It consisted of two parts of assessing different risk factors (i.e. environmental conditions, angle of gaze, years of VDD use) with contact lens use and Ocular Surface Disease Index (OSDI) questionnaire. The OSDI scores of the entire sample who suffer from dry eye and the subgroup using contact lenses were calculated. The relationship between different risk factors with the OSDI scores was also assessed.

\section{RESULTS}

274 young adults from college students and academic staff ( 216 female, 58 male) were suffering from eye dryness. 88 of the 274 participants wore contact lenses. The mean OSDI scores of the 274 young adults was 32.92. Mean OSDI scores in contact lens wearers and non-wearers were 34.36 and 32.24 respectively $(p<0.01)$. There was a statistically significant relationship between OSDI score and indoor environmental conditions in computer using VDD group. Using a computer in a dark environment and above the line of sight resulted in a higher OSDI scores. Females who wore contact lenses whilst using a computer for more than three years had significantly higher OSDI scores than non-wearer females. Tablet type VDD use increased the mean ODSI scores of the contact lens wearers significantly.

\section{CONCLUSIONS}

Dry eye symptoms were shown to be increased in the contact lens wearer group with the increased duration of computer VDD use, decreased indoor environmental brightness conditions, and above the line of sight.

\section{Background}

The 5th European Survey on Working Conditions had revealed the exponential increase in computer use over the last twenty years.[1] Especially, the use of handheld electronic devices such as smartphones and tablets had also increased considerably and reached almost saturation levels with 95 percent among the individuals aged 18-34 in 2017.[1] Consequently, a group of ocular and vision symptoms known as 
Computer Vision Syndrome (CVS) has emerged among the visual display device (VDD) users. CVS was defined by the American Optometric Association as a group of eye and vision problems associated with the computer, tablet, e-reader, and smartphone use for long hours.[2] The most common symptoms of CVS were eye strain, headaches, burning eyes, light sensitivity, blurred vision, dry eyes, neck and shoulder pain.[2] It was predicted that about 60 million people suffer from CVS in the world and that one million new cases emerge every year.[3]

Dry eye disease (DED) was a multifactorial ocular surface disease that was the result of inadequate tear production and/or increasing evaporation over ocular surface both of which were resulted in inadequate moistening of the eye.[4] DED might result in serious complications from reversible ocular discomfort due to ocular surface damage to the irreversible visual impairment. Besides the discomfort of the patient, disease interferes with daily life and had unfavorably affected the daily activities such as driving, reading, watching TV, and using a computer. [5] It was more common in females because of changing hormone levels during pregnancy and menopause.[6] Also, some factors penetrating the daily life such as indoor environment could lead to DED which was becoming widespread among the young adults in continuing COVID-19 pandemic.[7] Additionally, low humidity and temperature conditions of the environment were already known as triggering factors for DED.[8]

Recently computer use and contact lens wear were demonstrated as major risk factors in DED guidelines. [9] There were approximately 140 million contact lens wearers and the number of wearers was increasing each year. There was a big diversity of contact lens types with different wear modalities. Many contact lens wearers reported dryness as the initial symptom. Contact lens wear was associated with a 12-fold increase in risk of experiencing dry eye disease and moreover, more than $50 \%$ of the contact lens wearers experienced dry eye symptoms. This requires physicians to stay current in matters concerning contact lens related dry eye disease consequences.[10]

This study aimed to investigate the relationship of using various visual display devices in the development of dry eye disease in young adults specifically using contact lenses.

\section{Methods}

This was a cross-sectional web-based survey study conducted at tertiary level university hospital that aimed to state frequency and risk factors of eye dryness among young adults (with or without contact lenses) of VDD users.

This study was performed in line with the principles of the Declaration of Helsinki. Approval was granted by the Ethics Committee of the Acibadem University (2015-12/8).

The target sample consisted of 568 randomly chosen participants which included graduate and undergraduate students, academic staff and administrative staff of Acibadem University. Participation was voluntary and anonymous. The survey commenced with an information letter and informed consent was obtained from each participant. It can be reached online as an appendix. 
Participants other than young adults (defined as 15-29 years of age) [11] with systemic illnesses and whose OSDI scores of zero were excluded from the study. In addition to analysis of the entire sample, answers of the contact lens wearers were also analyzed and presented separately from non-wearers.

The survey was hosted in Google Forms, sent via e-mail to the participants. It consisted of two parts of assessing different risk factors (i.e. environmental conditions, angle of gaze, years of VDD use) with contact lens use and Ocular Surface Disease Index (OSDI) questionnaire. First part included demographic data, experienced eye-symptoms, visual tasks during the day (duration, distance and viewing level as using computer, laptop, smartphone, hardcopy reading), ophthalmic drug use. The second part specifically focused on contact lens wearers and here contact lens usage habits, dry eye symptoms were asked. The participants answered the questions by self-administration.

Questions in both parts were grouped under 3 subclasses: ocular symptoms, vision-related function and environmental triggers. All questions were graded between 0-4; 0 indicates never, 1 indicates sometimes, 2 indicates usually, 3 indicates most of the time and 4 indicates always. The total OSDI score of the entire population was also calculated as assessed by Schiffman using the following formula.

OSDIC $=($ sum of scores $) \times 25 /$ (number of questions answered $)$

\section{Statistical methods}

Data was analyzed using the statistical program $\mathrm{R}$ version 3.5.0.[12, 13] Linear regression analyses were conducted as total OSDI score being the dependent variable. Shapiro-Wilk Normality and Bartlett Homogeneity Tests were done on residuals of the model to ensure normal and homogenous distribution. Residuals were homogeneous with abnormal distribution. To normalize the data, Box Cox Transformation was conducted, and best lambda was calculated as 0.6. After the transformation, linear regression analyses were reconducted using 0.6 th power of total OSDI scores. Once again Shapiro-Wilk Normality and Bartlett Homogeneity Tests were done on residuals of the model to ensure normal and homogenous distribution. Residuals were homogeneously and normally distributed. To ensure effective sample size, power analysis was also carried out and it had a mean value of 0.81 .

\section{Results}

\section{Entire Cohort}

In total, 568 individual responses were collected from the survey and 342 participants experienced the feeling of dry eye. 60 participants were older than 29 years old and 49 participants had systemic illnesses. After the exclusion, 274 young adults were included in the analysis. 88 of 274 participants were wearing contact lenses.

There were 216 female and 58 male participants with an average age of 20.97 years. Table 1 showed the demographics of the participants. The average age of women and men were 20.86 and 21.36 years, 
respectively $(p=0.18)$. Various risk factors of computer use habits associated with dryness in contact lens wearers and non-wearers were demonstrated in Table 2.

The average OSDI score of the entire cohort was 32.92 units and females were likely to present a higher mean OSDI score than males $(p<0.01)$. Mean OSDI scores in CL wearers and non-wearers were 34.36 and 32.24 respectively and this difference was statistically significant $(p<0.01)$.

Table 3 showed the various risk factors which had a statistically significant effect on OSDI scores of the entire cohort that was obtained from linear regression models. One hundred fifty-nine individuals (58\%) were not using a computer or using it less than seven days a week. Females who were not using a computer or even using less than seven days in a week had significantly higher mean OSDI scores than males $(p<0.01)$. There was no significant relation found between OSDI scores of participants with duration of VDD use in an hour, a day, or the time elapsed since the initiation of use ( $p=0.07$ computer, $p=0.89$ tablet, $p=0.68$ mobile phone, daily hour; $p=0.77$ computer, $p=0.64$ tablet, $p=0.41$ mobile phone).

Using a VDD in a dark environment resulted in statistically significant higher OSDI scores when compared with VDD users in bright conditions $(p=0.03)$. This subclass of 67 VDD users in dark environment also had significantly higher OSDI scores than non-computer users $(p=0.01)$.

Majority of the participants were using a laptop, $75.55 \%$ (207 people). Of the total computer users, only $6.93 \%$ (19 people) were using a Personal Computer (PC). There was no significant difference in OSDI scores between participants using desktop computers and non-computer users $(p=0.20)$ but laptop users had significantly higher OSDI scores than non-computer users $(p=0.04)$. Participants using both laptops and desktops had an even greater OSDI score than non-computer users $(p<0.01)$.

30.29 percent of the participants reported that they were looking at the computer screen from a distance of less than $50 \mathrm{~cm}$ proximity and those had significantly higher OSDI scores than others more specifically non-users $(p=0.01)$.

Majority of the participants were using a screen filter. Participants using a computer with a screen filter had significantly higher OSDI scores than participants that stated they do not use a computer in the survey $(p=0.03)$. Participants using a computer without a screen filter had also even greater statistically significant increase in OSDI scores when compared to participants that stated they do not use a computer in the survey $(p=0.01)$. Participants which were not using screen filters had higher OSDI scores than participants who were using screen filters, however, this association was not found to be statistically significant.

Although participants using a computer with bright screens had significantly higher OSDI scores than non-computer users $(p=0.02)$, there was no statistically significant difference between OSDI scores of participants using a computer with dark screens to those using bright screens.

It was showed that using a computer above the line of sight did not cause a significant effect on the OSDI score. However, participants using computers below the eye alignment had significantly higher 
OSDI scores than non-computer users $(p=0.02)$.

\section{Contact Lens Wearers Cohort}

Table 4 showed the various risk factors which had a statistically significant effect on OSDI scores of contact lens wearers (CLW) that was obtained from linear regression models. Participants stating a feeling of dryness in their eyes had significantly higher ODSI scores than participants who stated that they did not feel dryness $(p=0.02)$. Females were likely to have higher OSDI scores than males and this was also statistically significant $(P=0.03)$.

Using a tablet increased the ODSI score of CLWs significantly $(p=0.04)$. Females who wore contact lenses and used a computer for more than three years had significantly higher OSDI scores than non-contact lens wearer females using a computer for more than three years $(p<0.001)$.

The environment in which the computer is used had a statistically significant effect on OSDI scores of CLWs and using the computer in a dark environment increased the OSDI score $(p=0.02)$. In addition, using a computer above the line of sight increased the OSDI score $(p=0.01)$.

\section{Discussion}

The present study was based on a self-administrative survey including the OSDI questionnaire and conducted among young adults. The correlation of eye dryness with VDD use and contact lens wearing habits among young adults was assessed. It was found that the mean OSDI score of the participants who had been wearing contact lenses was increased to 34.36 from the value of 32.24 in non-wearer young adults. In addition to that, there was a statistically significant difference of OSDI scores was found between genders.

Higher OSDI scores in females compared with males were found in this cohort, and additionally, that dry eye disease was more common in females. There were several different studies in English literature about the difference in the OSDI scores between males and females [3,14]. Some of these studies indicated that males had a higher OSDI score[14,15], whilst others supported our finding with the outcome that showed females having higher OSDI scores. $[16,17]$

Our study showed that the distance to the computer screen had a statistically significant enhancing effect on OSDI score. Participants using a computer at a distance less than $50 \mathrm{~cm}$ showed higher OSDI scores and there were several studies supporting our findings.[18] The optimum distance was indicated by several authors as approximately $60-100 \mathrm{~cm}$ away from the computer screen to minimize the risk of developing DED.[19, 20]

The use of a tablet or smartphone did not cause any significant change in OSDI scores of participants in terms of any parameter such as screen brightness, distance to the screen, angle of gaze, etc. This result might be related to using handheld devices in various gaze angles including small, most commonly, and high. It was shown that using a computer in higher gaze angles results in increased tear evaporation and 
therefore increased ocular discomfort symptoms.[21] Using devices in smaller gaze angles might be safer than using in high gaze angles. Yet, more investigation is required to be able to make comparisons. The studies conducted by Golebiowski et al. and Madudoc et al. also found no change in tear volume with the usage of tablets or smartphones, respectively. Although reduced tear volume is reported with computer use by many studies.[22, 23]

The majority of the studies in the literature indicated that contact lens use is a furthermost reason for DED. [5, 24-26] We found significantly higher OSDI scores among the females wearing contact lenses longer than three years compared with the non-wearers in our study. Present study had shown that CLWs using a computer for more than three years have significantly higher OSDI scores than those using a computer for less than three years. There were similar studies supporting our study with similar results [27] as well as some opposing studies stating no correlation between using a computer and DED.[24] We believe that using a computer over a long term resulted in infrequent blinking that resulted in insufficient wetting of the ocular surface. [19]

It was found that the indoor environmental factors such as the brightness of the workplace had an effect on OSDI scores of CLWs. Using a computer in a dark environment increased the OSDI score significantly so CLWs using a computer in a bright environment had a decreased risk of DED. However, there were very limited studies that were concerned about the brightness of the environment, one study pointed out that there was no association between the brightness of the environment and the OSDI scores. [28] On the other hand, another study stated that the weak lighting condition could affect the presence of complaints related to the CVS. [29]

Line of sight was stated as another risk factor that had a possible impact on the OSDI scores of CLWs. The current study showed that using a computer above the line of sight increased the OSDI score. Additionally, some studies lined up with a statistically significant relationship between OSDI scores and angle of gaze[19, 30,31], although some limited studies asserted that there was no association between the line of sight and DED.[3] We believe that using the computer in a proper position is important to avoid DED. Due to the upper part of the ocular surface was protected under the effect of the upper eyelid in case of using a computer below the line of sight. [32]

This study was one of the most comprehensive studies in terms of the number of variables tested. In contrast to the extensive literature on computer usage habits, there is limited literature on handheld electronic devices assessed in the context of CVS. This study contributed to the literature by a detailed investigation of ocular disturbances related to both computer and handheld electronic devices among the young adults. However, one limitation of our study was that there was a disparity in numbers between the number of male and female participants due to nonhomogeneous gender distribution in this institute.

\section{Conclusions}

In the present study, we found that the female gender has a greater tendency for developing DED. In our contact lens wearer cohort; duration of computer use(years), brightness or darkness as an indoor 
condition, and angle of gaze were found to have a statistically significant relation with the development of VDD associated eye dryness.

\section{Declarations}

1) Ethics approval and consent to participate

The study was adhered to the provisions of the Declaration of Helsinki and under the approval of the Acıbadem University Ethical Committee.

Date and Reference number of Ethical Committee Approval:

22.10.2015

$2015-12 / 8$

2) Consent for publication

Not applicable.

\section{3) Availability of data and materials}

The datasets used and/or analyzed during the current study are available from the corresponding author on reasonable request.

\section{4) Competing interests}

The authors have no financial or proprietary interests in any material discussed in this article.

\section{5) Funding}

No funds, grants, or other support was received.

\section{6) Authors' contributions}

EA collected the data and wrote the paper. AE conceived and designed and performed the analysis. GF and CA contributed to data collection, interpreting results, and reviewing the paper. ARCC was the corresponding author and contributed to the design and implementation of the research, to the analysis of the results, and to the writing of the manuscript. All authors read and approved the final manuscript.

\section{7) Acknowledgements}

Not applicable

\section{References}


1. (2017) Mobile Consumer Survey: The Australian cut 2017: Deloitte. 2017 [cited 2019; Available from: https://www2.deloitte.com/content/dam/Deloitte/au/Documents/technology-mediatelecommunications/deloitte-au-tmt-mobile-consumer-survey-2017-211117-final.pdf.

2. Computer vision syndrome. [cited 2021; Available from: https://www.aoa.org/healthy-eyes/eye-andvision-conditions/computer-vision-syndrome?sso=y.

3. Ranasinghe P, Wathurapatha WS, Perera YS, Lamabadusuriya DA, Kulatunga S, Jayawardana N, and Katulanda P (2016) Computer vision syndrome among computer office workers in a developing country: an evaluation of prevalence and risk factors. BMC Res Notes 9https://doi.org/10.1186/s13104-016-1962-1

4. Courtin R, Pereira B, Naughton G, Chamoux A, Chiambaretta F, Lanhers C, and Dutheil F (2016) Prevalence of dry eye disease in visual display terminal workers: a systematic review and metaanalysis. BMJ Open 6(1). https://doi.org/10.1136/bmjopen-2015-009675

5. Bakkar MM, Shihadeh WA, Haddad MF, and Khader YS (2016) Epidemiology of symptoms of dry eye disease (DED) in Jordan: A cross-sectional non-clinical population-based study. Cont Lens Anterior Eye 39(3). https://doi.org/10.1016/j.clae.2016.01.003

6. Peck T, Olsakovsky L, and Aggarwal S (2017) Dry Eye Syndrome in Menopause and Perimenopausal Age Group. J Midlife Health 8(2). https://doi.org/10.4103/jmh.JMH_41_17

7. Chiva A (2011) Electrophoresis of tear proteins as a new diagnostic tool for two high risk groups for dry eye: computer users and contact lens wearers. J Med Life 4(3).

8. van Setten G, Labetoulle M, Baudouin C, and Rolando M (2016) Evidence of seasonality and effects of psychrometry in dry eye disease. Acta Ophthalmol 94(5). https://doi.org/10.1111/aos.12985

9. Bron AJ, de Paiva CS, Chauhan SK, Bonini S, Gabison EE, Jain S, Knop E, Markoulli M, Ogawa Y, Perez V, Uchino Y, Yokoi N, Zoukhri D, and Sullivan DA (2017) TFOS DEWS II pathophysiology report. Ocul Surf 15(3). https://doi.org/10.1016/j.jtos.2017.05.011

10. Lim CHL, Stapleton F, and Mehta JS (2018) Review of Contact Lens-Related Complications. Eye Contact Lens 44 Suppl 2https://doi.org/10.1097/ICL.0000000000000481

11. LAG BAOLMBRR (2006) Cancer Epidemiology in Older Adolescents and Young Adults 15 to 29 Years of Age, Including SEER Incidence and Survival: 1975-2000. 2006 [cited 2021; Available from: https://seer.cancer.gov/archive/publications/aya/.

12. Team R (2018) R: A language and environment for statistical computing. 2018 2019]; Available from: https://www.R-project.org/.

13. BR WV (2002) in Modern Applied Statistics with S. , Springer: New York.

14. Portello JK, Rosenfield M, Bababekova Y, Estrada JM, and Leon A (2012) Computer-related visual symptoms in office workers. Ophthalmic Physiol Opt 32(5). https://doi.org/10.1111/j.14751313.2012.00925.x

15. Ahn JH, Choi YH, Paik HJ, Kim MK, Wee WR, and Kim DH (2017) Sex differences in the effect of aging on dry eye disease. Clin Interv Aging 12https://doi.org/10.2147/CIA.S140912 
16. Toomingas A, Hagberg M, Heiden M, Richter H, Westergren KE, and Tornqvist EW (2014) Risk factors, incidence and persistence of symptoms from the eyes among professional computer users. Work 47(3). https://doi.org/10.3233/WOR-131778

17. Uchino M, Dogru M, Uchino Y, Fukagawa K, Shimmura S, Takebayashi T, Schaumberg DA, and Tsubota K (2008) Japan Ministry of Health study on prevalence of dry eye disease among Japanese high school students. Am J Ophthalmol 146(6). https://doi.org/10.1016/j.ajo.2008.06.030

18. Jaschinski W, Heuer $\mathrm{H}$, and Kylian $\mathrm{H}$ (1999) A procedure to determine the individually comfortable position of visual displays relative to the eyes. Ergonomics 42(4).

https://doi.org/10.1080/001401399185450

19. Vertinsky T and Forster B (2005) Prevalence of eye strain among radiologists: influence of viewing variables on symptoms. AJR Am J Roentgenol 184(2). https://doi.org/10.2214/ajr.184.2.01840681

20. Parihar JK, Jain VK, Chaturvedi P, Kaushik J, Jain G, and Parihar AK (2016) Computer and visual display terminals (VDT) vision syndrome (CVDTS). Med J Armed Forces India 72(3). https://doi.org/10.1016/j.mjafi.2016.03.016

21. Tsubota K and Nakamori K (1995) Effects of ocular surface area and blink rate on tear dynamics. Arch Ophthalmol 113(2). https://doi.org/10.1001/archopht.1995.01100020037025

22. Wu H, Wang Y, Dong N, Yang F, Lin Z, Shang X, and Li C (2014) Meibomian gland dysfunction determines the severity of the dry eye conditions in visual display terminal workers. PLoS One 9(8). https://doi.org/10.1371/journal.pone.0105575

23. Nakamura S, Kinoshita S, Yokoi N, Ogawa Y, Shibuya M, Nakashima H, Hisamura R, Imada T, Imagawa T, Uehara M, Shibuya I, Dogru M, Ward S, and Tsubota K (2010) Lacrimal hypofunction as a new mechanism of dry eye in visual display terminal users. PLoS One 5(6). https://doi.org/10.1371/journal.pone.0011119

24. Garza-Leon M, Valencia-Garza M, Martinez-Leal B, Villarreal-Pena P, Marcos-Abdala HG, CortezGuajardo AL, and Jasso-Banda A (2016) Prevalence of ocular surface disease symptoms and risk factors in group of university students in Monterrey, Mexico. J Ophthalmic Inflamm Infect 6(1). https://doi.org/10.1186/s12348-016-0114-z

25. Begley CG, Caffery B, Nichols KK, and Chalmers R (2000) Responses of contact lens wearers to a dry eye survey. Optom Vis Sci 77(1). https://doi.org/10.1097/00006324-200001000-00012

26. Tauste A, Ronda E, Molina MJ, and Segui M (2016) Effect of contact lens use on Computer Vision Syndrome. Ophthalmic Physiol Opt 36(2). https://doi.org/10.1111/opo.12275

27. Rosenfield M (2011) Computer vision syndrome: a review of ocular causes and potential treatments. Ophthalmic Physiol Opt 31(5). https://doi.org/10.1111/j.1475-1313.2011.00834.x

28. Sa EC, Ferreira Junior M, and Rocha LE (2012) Risk factors for computer visual syndrome (CVS) among operators of two call centers in Sao Paulo, Brazil. Work 41 Suppl 1https://doi.org/10.3233/WOR-2012-0636-3568

29. Stella C. Chiemeke Member I, Allen E. Akhahowa, Olajire B. Ajayi Evaluation of Vision-Related Problems amongst Computer Users: A Case Study of University of Benin, Nigeria, in Proceedings of 
the World Congress on Engineering. 2007: London, UK.

30. Loh K and Redd S (2008) Understanding and preventing computer vision syndrome. Malays Fam Physician 3(3).

31. Mowatt L, Gordon C, Santosh ABR, and Jones T (2018) Computer vision syndrome and ergonomic practices among undergraduate university students. Int $\mathrm{J}$ Clin Pract 72(1). https://doi.org/10.1111/ijcp.13035

32. Thomson WD (1998) Eye problems and visual display terminals-the facts and the fallacies. Ophthalmic Physiol Opt 18(2).

\section{Tables}

\begin{tabular}{ll}
\hline Table l. Demographics of the study cohort & \\
\hline Gender (number of respondents) & \\
Male & 58 \\
Female & 216 \\
& \\
Age (average) & \\
Male & 21.36 \\
Female & 20.86 \\
Total & 20.97 \\
\hline
\end{tabular}




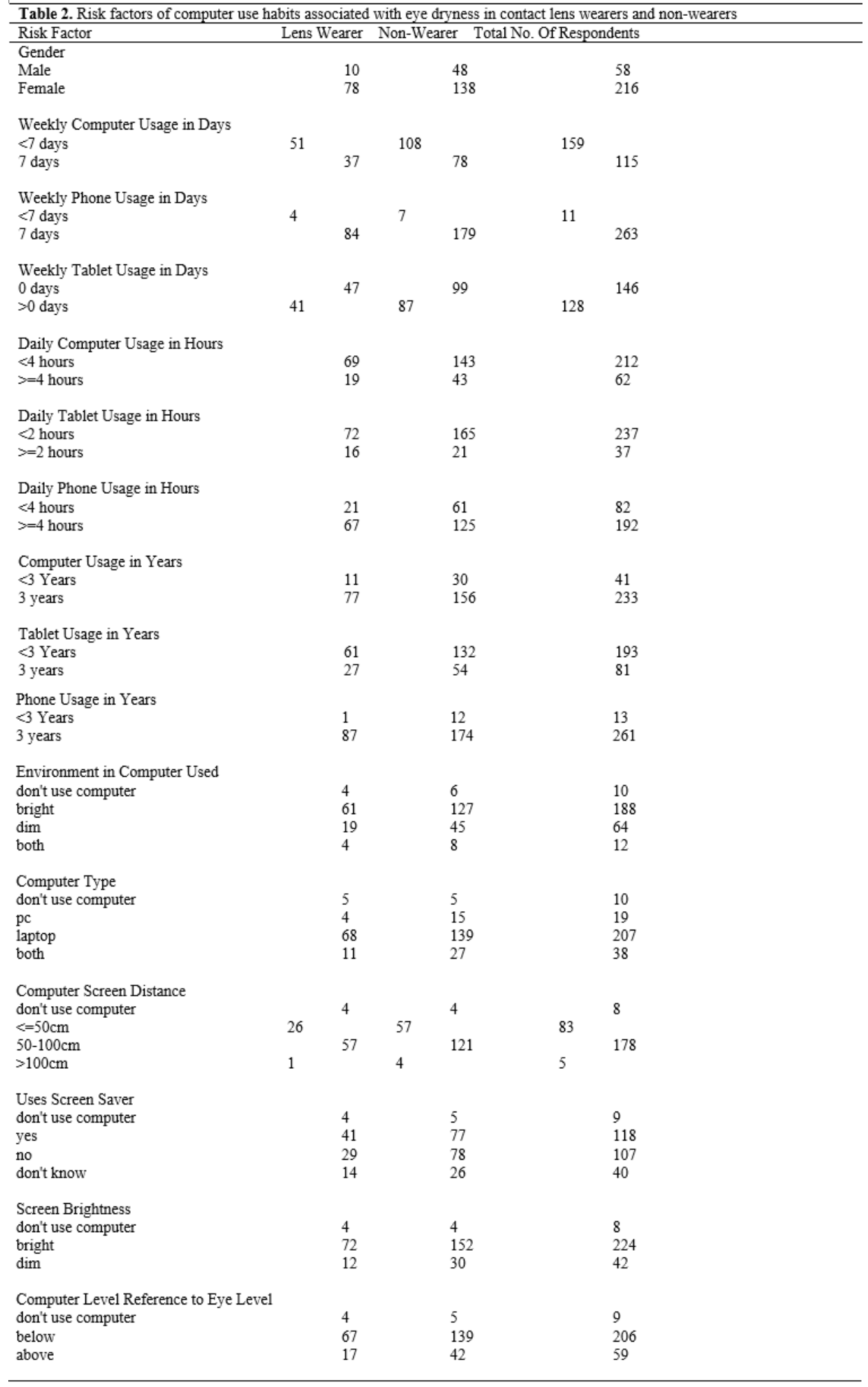


Table 3. Risk factors which had significant effect on OSDI scores, independent variables, $B$ Coefficients, $P$ values and confidence intervals (CI)

\begin{tabular}{|c|c|c|c|c|}
\hline Risk Factor & Variable(B's) & B Coefficients & $\mathrm{CI}$ & P Value \\
\hline \multicolumn{5}{|c|}{ Environment in which Computer Used } \\
\hline & Age & 0.20 & $0.06 \_0.33$ & $<0.01$ \\
\hline & Gender(Female) & 1.75 & $0.95_{-}^{-} 2.55$ & $<0.01$ \\
\hline & Lens Usage(No) & -0.16 & $-0.85-0.53$ & 0.65 \\
\hline & Bright Environment & 1.47 & $-0.24_{-}^{-} 3.17$ & 0.09 \\
\hline & Dim Environment & 2.32 & $0.53 \_4.11$ & 0.01 \\
\hline & Both (Dim\&Bright) & 2.65 & $0.39_{-}^{-} 4.91$ & 0.02 \\
\hline & Intercept $\mathrm{a}^{\mathrm{a}}$ & 4.29 & $2.37^{-} 6.21$ & $<0.01$ \\
\hline \multicolumn{5}{|c|}{ Environment in which Computer Used; bright } \\
\hline & Age & 0.20 & $0.06 \_0.33$ & $<0.01$ \\
\hline & Gender(Female) & 1.75 & $0.95 \_2.55$ & $<0.01$ \\
\hline & Lens Usage(No) & -0.16 & $-0.85_{-}^{-} 0.53$ & 0.60 \\
\hline & Envr.; bright (dim) & 0.85 & $0.09-1.62$ & 0.03 \\
\hline & Envr.; bright (both) & 1.19 & $-0.40_{-}^{-} 2.77$ & 0.10 \\
\hline & Envr.; bright (no comp.) & -1.47 & $-3.17_{-}^{-} 0.24$ & 0.09 \\
\hline & Intercept $\mathrm{t}^{\mathrm{a}}$ & 5.75 & $4.69 \_6.82$ & $<0.01$ \\
\hline \multicolumn{5}{|c|}{ Computer Type } \\
\hline & Age & 0.16 & $0.03 \_0.30$ & 0.02 \\
\hline & Gender (Female) & 1.70 & $0.91_{-} 2.50$ & $<0.01$ \\
\hline & Lens Usage (No) & -0.19 & $-0.88 \_0.51$ & 0.59 \\
\hline & Computer Type (pc) & 1.36 & $-0.71-3.43-$ & 0.20 \\
\hline & Computer Type (laptop) & 1.77 & $0.06 \_3.48$ & 0.04 \\
\hline & Computer Type (both) & 2.65 & $0.77_{-}^{-} 4.52$ & 0.01 \\
\hline & Intercept $\mathrm{t}^{\mathrm{a}}$ & 4.30 & $2.38_{-}^{-} 6.22$ & $<0.01$ \\
\hline \multicolumn{5}{|c|}{ Computer Screen Distance (CSD) } \\
\hline & Age & 0.16 & $0.02 \_0.29$ & 0.02 \\
\hline & Gender(Female) & 1.73 & $0.93-2.52$ & $<0.01$ \\
\hline & Lens Usage(No) & -0.18 & $-0.88_{-}^{-} 0.51$ & 0.60 \\
\hline & $\operatorname{CSD}(<=50 \mathrm{~cm})$ & 2.54 & $0.58 \_4.50$ & 0.01 \\
\hline & $\operatorname{CSD}(50-100 \mathrm{~cm})$ & 1.90 & $-0.01_{-}^{-} 3.81$ & 0.05 \\
\hline & $\mathrm{CSD}(>100 \mathrm{~cm})$ & 2.02 & $-0.99^{-} 5.03$ & 0.19 \\
\hline & Intercept $\mathrm{t}^{\mathrm{a}}$ & 4.05 & 1.976 .14 & $<0.01$ \\
\hline & Intercept $\mathrm{t}^{\mathrm{a}}$ & 4.05 & $1.97 \_6.14$ & $<0.01$ \\
\hline \multicolumn{5}{|c|}{ Uses Screen Saver (SS) } \\
\hline & Age & 0.16 & $0.03 \_0.30$ & 0.02 \\
\hline & Gender(Female) & 1.73 & $0.93 \_2.53$ & $<0.01$ \\
\hline & Lens Usage(No) & -0.21 & $-0.90_{-}^{-} 0.49$ & 0.56 \\
\hline & Uses SS (yes) & 1.97 & $0.15 \_3.79$ & 0.03 \\
\hline & Uses SS (no) & 2.37 & $0.54-4.21$ & 0.01 \\
\hline & Uses SS (don't know) & 1.63 & $-0.31_{-}^{-} 3.58$ & 0.10 \\
\hline & Intercept $\mathrm{t}^{\mathrm{a}}$ & 4.08 & $2.08 \_6.08$ & $<0.01$ \\
\hline \multicolumn{5}{|c|}{ Screen Brightness } \\
\hline & Age & 0.16 & $0.03 \_0.30$ & 0.02 \\
\hline & Gender(Female) & 1.60 & $0.81-2.40$ & $<0.01$ \\
\hline & Lens Usage(No) & -0.19 & $-0.88 \_0.51$ & 0.60 \\
\hline & Bright Screen & 2.19 & $0.28 \_4.09$ & 0.02 \\
\hline & Dim Screen & 1.59 & $-0.45^{-} 3.64$ & 0.13 \\
\hline & Intercept $\mathrm{t}^{\mathrm{a}}$ & 4.16 & $2.07 \_6.24$ & $<0.01$ \\
\hline \multicolumn{5}{|c|}{ Computer Level Reference to Eye Level } \\
\hline & Age & 0.14 & $0.00 \_0.28$ & 0.05 \\
\hline & Gender(Female) & 1.65 & $0.86_{-}^{-} 2.44$ & $<0.01$ \\
\hline & Lens Usage(No) & -0.20 & $-0.89 \_0.50$ & 0.58 \\
\hline & Below the Line of Sight & 1.49 & $-0.30-3.29$ & 0.10 \\
\hline & Above the Line of Sight & 2.27 & $0.37 \_4.17$ & 0.02 \\
\hline & Intercept $\mathrm{t}^{\mathrm{a}}$ & 4.62 & $2.66_{-}^{-} 6.58$ & $<0.01$ \\
\hline
\end{tabular}

(Age=18; Gender=Male; Lens Usage=Yes)

b How to interpret the table: In "Enviroment in Computer Used" subcategory, $\beta_{0}$ incidates the intercept, which is the mean OSDI scores of males who use contact lenses and are 18 years old. B 1 indicates Age, and every one unit increase in age is associated with 0.2 increase in OSDI score and this is statistically significant. $\beta_{2}$ indicates Gender. Females' mean OSDI score is 1.75 units higher than males and this is statistically significant. $\beta_{3}$ indicates Lens Usage, non-lens users score 0.16 units lower in OSDI compared to lens users but this difference is not statistically significant. $\beta_{4}$ indicates Bright Environment, and people who use computers in bright environments score 1.47 units higher in OSDI compared to non-computer users but this difference is not statistically significant. $\beta_{5}$ indicates Dim Environment, people who use computer in dim enviroment compared to non-computer users score 2.32 units higher in OSDI and this difference is statistically significant. $\beta_{6}$ indicates Both(Dim and Bright) Environments and people who use computers in both dim and bright environments score 2.65 units higher in OSDI and this difference is statistically significant. All results in other subcategories can be interpreted using this example. 


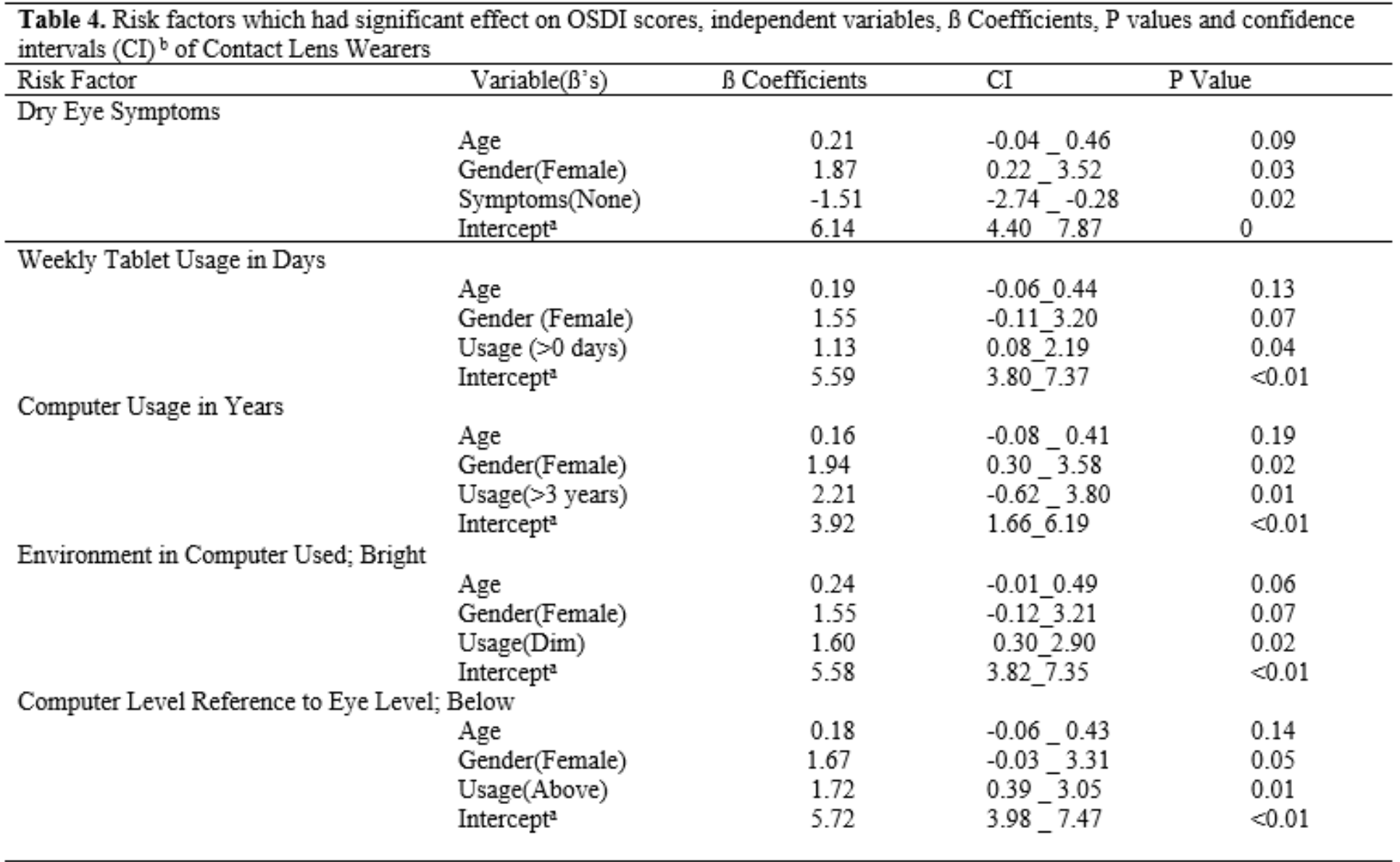

a (Age=18; Gender=Male; Lens Usage=Yes)

${ }^{b}$ How to interpret the table: In "Enviroment in Computer Used" subcategory, $\beta_{0}$ incidates the intercept, which is the mean OSDI scores of males who use contact lenses and are 18 years old. Blindicates Age, and every one unit increase in age is associated with 0.2 increase in OSDI score and this is statistically significant. $\beta_{2}$ indicates Gender. Females' mean OSDI score is 1.75 units higher than males and this is statistically significant. $\beta_{3}$ indicates Lens Usage, non-lens users score 0.16 units lower in OSDI compared to lens users but this difference is not statistically significant. $\beta_{4}$ indicates Bright Environment, and people who use computers in bright environments score 1.47 units higher in OSDI compared to non-computer users but this difference is not statistically significant. $\beta_{5}$ indicates Dim Environment, people who use computer in dim enviroment compared to non-computer users score 2.32 units higher in OSDI and this difference is statistically significant. $\beta_{6}$ indicates Both(Dim and Bright) Environments and people who use computers in both dim and bright environments score 2.65 units higher in OSDI and this difference is statistically significant. All results in other subcategories can be interpreted using this example.

\section{Supplementary Files}

This is a list of supplementary files associated with this preprint. Click to download.

- Appendix.docx 